\title{
Viabilidade econômica do financiamento de uma unidade armazenadora de grãos em Sorriso (MT)
}

\author{
Flávio Carlos Dalchiavon ${ }^{1}$ \\ Danilo Teodoro Mattos da Silva ${ }^{2}$ \\ Marcelo Brondani ${ }^{3}$
}

\section{Resumo}

A região Médio Norte do estado de Mato Grosso possui grande área dedicada à produção de soja e milho, porém, a capacidade estática da região está aquém da necessária. Tendo em vista essa oportunidade, foi elaborado um projeto para testar a viabilidade econômica da implantação de uma unidade armazenadora de grãos no município de Sorriso (MT). Utilizouse do Programa para Construção e Ampliação de Armazéns (PCA) que dispõe de uma linha de crédito via BNDES com juros subsidiados para construção de unidade armazenadora própria para produtores rurais, cooperativas e agroindústrias. A capacidade estática do armazém foi dimensionada para 101 mil sacas de grãos, capaz de armazenar $60 \%$ da produção anual de uma propriedade rural média de 1.000 hectares. Foram definidos orçamentos com custo de implantação e de manutenção da unidade por meio de pesquisa realizada com produtores rurais e empresas da região. O projeto utilizou de instrumentos de análise financeira de viabilidade: valor presente líquido (VPL), taxa interna de retorno (TIR) e taxa interna de retorno modificada (MTIR), além do "payback", com intuito de definir, num horizonte de 20 anos, o prazo mínimo para retorno. O projeto apresentou viabilidade econômica superior à taxa mínima de atratividade, resultando num VPL de R \$ 1.996.262,01, "payback" de doze anos, quatro meses e vinte sete dias, tornando-se rentável, uma vez que a vida útil do empreendimento é superior ao "payback". Após esta vida útil, o produtor terá agregado valor à produção, gerando ganhos/economias em sua propriedade rural.

Palavras-chave: Agronegócio, Finame, Investimento, Lucratividade

\section{Economic feasibility of funding a storage unit grain in Sorriso city (MT)}

\begin{abstract}
The mid-northern region of Mato Grosso state has a large area dedicated to the production of soybeans and corn crops, although the static capacity of the region is lower than necessary. Considering a great opportunity, was designed a project to test the economic viability of deploying a storage unit in Sorriso (MT). Through the Program for Construction and Expansion of Storage (PCA) that have a credit line through BNDES with interest subsidized for own storage unit building for farmers, cooperatives and agribusinesses. The static capacity of the warehouse was dimensioned to 101,000-grain bags, capable of storing $60 \%$ of annual production of an average rural property of 1,000 hectares. Budgets were defined with cost of

\footnotetext{
${ }^{1}$ Instituto Federal de Mato Grosso - Engenheiro Agrônomo, Doutor em Agronomia. flavio.dalchiavon@cnp.ifmt.edu.br

${ }^{2}$ Banco do Brasil. daniloteodoro@ bb.com.br

${ }^{3}$ Banco do Brasil. marcelobrondani@bb.com.br
} 
deployment and maintenance of the unit by means of a survey of farmers and companies in the region. The project used financial analysis tools viability, such as net present value (NPV), internal rate of return (IRR) and internal rate of return adjusted (MIRR) beyond Payback in order to define, in a 20-year horizon, the time limit for return. The project showed economic viability higher than the hurdle rate, resulting in a NPV of R \$1.996.262,01, Payback twelve years, four months and twenty seven days becoming profitable, once the life of the project is superior to Payback. After this life, the producer will have added worth to production, generating gains / savings on your farm.

Keywords: Agribusiness, Finame, Investment, Profitability

\section{INTRODUÇÃO}

O estado do Mato Grosso (MT) é destaque nacional na produção de grãos. A Companhia Nacional de Abastecimento estimou para a safra 2015/2016 que 23,35\% (44,19 milhões de toneladas) da produção total do país foi produzida no MT (CONAB, 2015a).

Apesar da pujança que o estado possui na agropecuária, ele enfrenta gargalos, como problemas na infraestrutura logística associados à baixa capacidade de armazenamento da sua produção, refletindo em congestionamento nas estradas, nos portos e, sobretudo, nos pátios das instalações para recepção das mercadorias a serem armazenadas (NOGUEIRA JUNIOR; TSUNECHIRO, 2011). A capacidade estática em MT em 2015 era de 33,463 milhões de toneladas, incluindo os produtores, tradings, cooperativas, governo etc. Desta forma, havia um déficit em torno de $24,27 \%$, porém, deve-se considerar que a safra 2015/2016 foi marcada por irregularidades climáticas, ocorrendo queda na produtividade devido à ausência de chuvas na região (CONAB, 2015b).

Uma unidade armazenadora própria, bem instalada técnica e geograficamente, torna o sistema produtivo mais eficiente e econômico. Armazenar o grão na propriedade apresenta vantagens, como melhor qualidade do produto; minimiza as perdas quantitativas e qualitativas que ocorrem na fazenda; gera economia de transporte (reduzindo o custo de frete); maior rendimento na colheita por evitar a espera dos caminhões nas filas e nas unidades coletoras ou intermediárias e taxas e descontos cobrados quando o produto é armazenado em armazém terceirizado. Destaca-se ainda a possibilidade de comercializar a produção em melhores períodos (entressafra), onde a oferta se torne menor e o preço maior (REGITANO-D'ACRE, 2009).

Ao longo de trinta anos o Brasil obteve grandes aumentos na produção de grãos, esse aumento não foi acompanhado pela capacidade estática, principalmente em regiões de fronteira agrícola. Nos anos 80 existiu um equilíbrio nos estados de SP e PR, porém a partir 
do século XXI houve uma inversão da relação superavitária na capacidade estática brasileira (AZEVEDO et al., 2008).

Conhecedor do cenário de déficit de armazenamento, o Governo Federal possui o Programa para Construção e Ampliação de Armazéns (PCA), linha de financiamento que faz parte do Plano Agrícola e Pecuário 2016/2017, lançado no início de Julho/2016 pelo Ministério da Agricultura, Pecuária e Abastecimento (MAPA). Foi destinado R\$ 1,4 bilhão em crédito aos agricultores, com juros anuais de 8,5\% e prazo de pagamento de 15 anos, com três anos de carência (MAPA, 2016).

O Instituto Mato-grossense de Economia Agropecuária (IMEA) segmentou o estado do Mato Grosso sob o ponto de vista agroeconômico, facilitando o levantamento de dados e dimensionamento da sua economia (IMEA, 2010). Sob esta ótica, destaca-se a macrorregião Médio Norte, que possue como polos econômicos as cidades de Sinop, Sorriso e Lucas do Rio Verde. Essa macrorregião é a maior produtora de grãos dentre as macrorregiões segmentadas, representando 35\% da área total de semeadura de safra verão (3.142.740 milhões de hectares), para safra 2015/2016 (IMEA, 2016a).

O município de Sorriso, localizado no Médio Norte de MT e com PIB de R\$ 3,66 bilhões em 2013 (IBGE, 2016), apresenta topografia e clima favoráveis à culturas de grãos, cuja sua produção está estimada em 10.067.904 de toneladas para safra 2016/2017 (IMEA, 2016b).

Assim, objetivou-se com este trabalho determinar a viabilidade econômica da instalação de uma unidade armazenadora de grãos na macrorregião Médio Norte de Mato Grosso, em nível de propriedade rural, por meio da linha de financiamento PCA.

O presente trabalho está estruturado da seguinte forma: introdução, objetivo, material e métodos, apresentação e análise de resultados obtidos e conclusões.

\section{MATERIAL E MÉTODOS}

\subsection{Dimensionamento do Projeto}

O estudo de viabilidade econômica (ano base 2016) foi dimensionado para uma propriedade rural no município de Sorriso, localizado no Médio Norte do estado de Mato Grosso, para simular a construção de unidade armazenadora contemplando a limpeza, secagem e padronização de grãos. 
A capacidade estática ideal de armazenagem nas fazendas é de 60 a $70 \%$ da produção anual bruta (COGO, 2013). Para esse projeto foi estipulado que a capacidade total de armazenamento do empreendimento será de $60 \%$ do total de grãos produzidos (safra de soja e safrinha de milho) de um produtor com área para semeadura de 1.000 hectares, sendo cultivado na primeira safra (verão) 1.000 hectares de soja e na segunda safra (inverno) 1.000 hectares de milho (buscando a otimização da área agricultável).

A produtividade média dos últimos seis anos agrícolas foi de $3.102 \mathrm{~kg} \mathrm{ha}^{-1}$ para soja e 5.662,80 $\mathrm{kg} \mathrm{ha}^{-1}$ para o milho na macrorregião Médio Norte de MT (IMEA, 2016b). Para este projeto foram utilizadas as produtividades de 3.480 (soja) e $6.600 \mathrm{~kg} \mathrm{ha}^{-1}$ (milho), sendo estas as produtividades médias obtidas no município de Sorriso (MT), que apresenta regime de chuvas bem definido e distribuído, proporcionando a semeadura de soja verão a partir de 15 de setembro, colheita antecipada a partir de final de dezembro e começo de janeiro e inicio da semeadura do milho safrinha na sequência. Desta forma, o projeto foi desenhado para um armazém com capacidade estática de 6.060 toneladas, considerando uma safra com 3.480 e 6.600 toneladas de soja e milho, respectivamente. Os custos de construção e implantação da estrutura de secagem e armazenamento de grãos (capacidade de 6.060) estão no valor total de $\mathrm{R} \$$ 3.865.329,52 (Anexo A).

A unidade armazenadora foi composta de dois silos com capacidade estática de 3.030 toneladas cada. O modelo do silo foi o vertical (silo bin, "upright storage" ou vertical "storage"). O material escolhido foi o alumínio por contar com facilidade de instalação e melhor conservação dos grãos, permitindo armazenagem por longo tempo, com vantagens na movimentação do grão (carga e descarga) e distribuição de calor e umidade mais uniformes, porém, devido à altura, pode ocorrer maior quebra de grãos na queda e maior custo na torre de serviço (REGITANO-D’ARCE, 2009).

\subsection{Custos}

A secagem e a armazenagem do produto pós-colheita são de suma importância para manter a qualidade do grão e impedir a perda das características físicas, químicas e biológicas da colheita. O grão tem de passar por dois processos antes de o seu acondicionamento ocorrer. O processo anterior à armazenagem chama-se padronização, que consiste na pré-limpeza para retirar impurezas. O segundo processo é a secagem para diminuir a atividade biológica no interior do grão e o transporte com descarga no interior do armazém para receber a injeção controlada de ar. Assim, o produto terá medição de temperatura e tratamento fitossanitário, 
além de prevenção e eliminação de insetos, se necessário (DAMBROSIO et al., 2009; BURKOT, 2014).

Um dos objetivos do armazenamento é comercializar os produtos agrícolas na época em que o preço é melhor. Para Batalha (2011), o agronegócio possui sazonalidades de oferta que estão em desacordo com a demanda de seus produtos, onde o armazenamento dos produtos possibilita uma coordenação de suprimentos em relação à demanda. Por esse motivo é importante o acondicionamento correto da produção para que a comercialização seja eficiente. Assim, foi utilizado o conceito de estoque para otimizar a comercialização sendo possível obter melhores preços devido a sazonalidade da oferta, visto que o objetivo foi manter o produto para obter preços melhores e aumentar a receita do produtor rural. Desta forma, restringe-se a oferta do produto na safra, reduzindo a volatilidade dos preços póscolheita.

Consideraram-se os custos de capital, de obsolescência, de armazenagem e custos diversos. O custo de capital corresponde ao custo de oportunidade do produto estocado. $\mathrm{O}$ custo de obsolescência pode ser calculado pela perda de valor do bem armazenado devido à deterioração ou perda do valor de mercado. $\mathrm{O}$ custo de armazenagem trata-se do custo de permanência nas instalações, preço do aluguel em instalações privadas ou em instalações próprias e a taxa por unidade do produto para limpeza e acondicionamento. Os custos diversos estão relacionados aos impostos, seguros ou perda de quantidade no transporte (BATALHA, 2011).

Os custos do projeto foram divididos em custos de implantação, montagem do armazém e custo de capital com máquinas e equipamentos. Os custos de armazenagem do empreendimento foram divididos em variáveis, que dependem do nível de atividade do armazém, e fixo, que ocorre não importando o nível de lotação do silo. Os custos de obsolescência foram definidos pela depreciação dos bens. Os custos com impostos trabalhistas (INSS, FGTS, $13^{\circ}$ salários e férias relativas) foram acrescidos ao custo unitário da mão-de-obra. O custo com quebra técnica de grãos foi definido conforme metodologia da ESALQ (2015).

Os custos com a armazenagem incluem salários com colaboradores, custos com energia, manutenção e material para realizar a secagem e padronização do grão, além de custos com quebra de grão. $\mathrm{N}$ os custos com o empreendimento (Tabela 1), utilizaram-se cinco colaboradores temporários para a safra, encarregados de serviços gerais, um classificador permanente e dois operadores de máquinas permanentes. Os custos envolvidos no processo de padronização e limpeza dos grãos foi definido por $\mathrm{R} \$ 0,50 \mathrm{sc}^{-1}$, conforme 
descrição de empresas de armazenagem do município de Sorriso (MT), referentes à energia elétrica e combustível para as caldeiras. O projeto foi elaborado com utilização de $100 \%$ da capacidade estática da estrutura, sendo que os custos variáveis expressaram capacidade ociosa nula.

Tabela 1- Custos de armazenagem do empreendimento

\begin{tabular}{|c|c|c|c|c|}
\hline Descrição & Quantidade & Meses & Valor Unitário & Valor Total \\
\hline & \multicolumn{2}{|l|}{--Toneladas-- } & \multicolumn{2}{|c|}{-----------R\$----------- } \\
\hline $\begin{array}{l}\text { Secagem, limpeza e } \\
\text { armazenagem }\end{array}$ & $10.080,00$ & - & 8,34 & $84.000,00$ \\
\hline \multirow[t]{2}{*}{ Quebra de grãos } & $10.080,00$ & 1 & 3,53 & $35.582,40$ \\
\hline & \multicolumn{2}{|c|}{------Unidade------ } & \multicolumn{2}{|c|}{----------------R\$--------------- } \\
\hline Funcionários extras para a safra & 5 & 4 & $4.752,00$ & $95.040,00$ \\
\hline Funcionário classificador & 1 & 13 & $5.848,62$ & $76.032,00$ \\
\hline Funcionário operador & 2 & 13 & $14.036,68$ & $182.476,80$ \\
\hline
\end{tabular}

Fonte: Dados fornecidos por produtores rurais de Sorriso (MT)

Para representar o custo de obsolescência utilizou-se a Lei $\mathrm{n}^{\circ} 12.973 / 14$, que determina o lucro real da pessoa jurídica para deduzir o imposto de renda da depreciação de máquinas e equipamentos. Para fins de cálculo de depreciação, foi utilizada a taxa anual de depreciação fixada pela Receita Federal do Brasil, Instrução Normativa nº 162/88. Adotou-se taxas de depreciação e vida útil diferenciadas para edificações, máquinas e equipamentos, móveis utensílios, instalações elétricas e computadores (Tabela 2).

Tabela 2- Depreciação e custo de obsolescência

Depreciação

Descrição

anual Vida útil Valor total

Depreciação anual 


\begin{tabular}{|c|c|c|c|c|c|}
\hline & & $\%$ & Anos & $\begin{array}{l}-------- \\
\end{array}$ & ------------ \\
\hline Edificações, & & 4 & 25 & $985.338,67$ & $39.413,55$ \\
\hline Máquinas & $\mathrm{e}$ & & & & \\
\hline Equipamentos & & & 10 & $2.272 .474,00$ & $227.247,40$ \\
\hline Instalações & & 10 & 10 & $98.000,00$ & $9.800,00$ \\
\hline Móveis e utensílios & & 10 & 10 & $12.250,00$ & $1.225,00$ \\
\hline Computadores & & 20 & 5 & $6.000,00$ & $1.200,00$ \\
\hline
\end{tabular}

Fonte: Instrução Normativa SRF nº 162, de 31 de dezembro de 1998

\subsection{Receitas}

A utilização de armazém próprio dinamiza a comercialização e otimiza o póscolheita, enfoque deste estudo, não cabendo as demais fases do processo produtivo.

As receitas que foram utilizadas não se tratam da venda ou beneficiamento de grãos para terceiros. Desta forma, as receitas serão apresentadas pela diferença de custo no armazenamento terceirizado privado ou no armazenamento próprio, sendo o próprio produtor responsável pela limpeza e padronização de toda sua produção, evitando os descontos e a perda do resíduo como subproduto. Assim, ocorrerão as seguintes receitas para a macrorregião Médio Norte do estado de MT:

I. Frete entre a lavoura da propriedade e o armazém recebedor mais próximo, sendo $\mathrm{R} \$$ 1,20 por saca de soja e R $\$ 1,30$ por saca de milho, conforme a metodologia do IMEA para a safra 2015/2016 (IMEA, 2015a).

II. Receita com subprodutos da soja, onde o processo de pré-limpeza do grão retira impurezas como grãos moídos no processo de colheita e palhas e cascas que se soltam (GOTTARDO; CESTARI, 2008). Esse material é conhecido como resíduo de limpeza de soja [RLS], que pode chegar a $12 \%$ de proteína. Esse produto é gerado na proporção de 2 quilos para cada 100 quilos de soja (Manella; BOIN, 2000). O resíduo do beneficiamento do milho também pode ser utilizado como alimentação para bovinos como forma de aditivo no processo de ensilagem. A produção de resíduo considerada foi de $2 \%$ do valor bruto total (PEREIRA et al., 2000). Desta forma, o produtor deixa de ter esses produtos com valor de proteína agregado. O valor de venda do RLS foi estipulado em R $\$ 250,00$ por tonelada assim como $\mathrm{R} \$ 190,00$ por tonelada para o resíduo do beneficiamento do milho, conforme pesquisa com produtores da macrorregião.

ReFAE - Revista da Faculdade de Administração e Economia, v. 9, n. 2, p. 166-190, 2019 
III. Redução nas despesas com custo de armazenagem, limpeza e beneficiamento da safra em armazém terceirizado fazem parte das receitas, pois com o armazenamento próprio o produtor não terá mais esses gastos. O custo total com essas etapas pós-colheita é de $\mathrm{R} \$ 2,45$ (milho) e R \$ 1,56 (soja) por saca, safra 2015/2016 (IMEA, 2015b).

IV. Otimização da comercialização do produto também é uma receita obtida através do armazenamento próprio, uma vez que o produtor rural possui mais controle sobre o momento de vender sua produção e aproveita os melhores preços de mercado. O produtor deixa de comercializar seu produto a preço de balcão, que é tabelado e padronizado por macrorregião, e utiliza o preço disponível como referência, podendo negociar de forma individual sua safra com tradings e unidades esmagadoras. Contudo, não foi obtida a diferença entre os preços balcão e disponível, pois não há dados oficiais.

A estratégia de comercialização utilizada foi de comercializar $87,00 \%$ da produção de soja (3.027,6 toneladas) e 45,91\% de milho safrinha (3.030 toneladas) no melhor período. Desta forma, potencializa a comercialização da soja, que possui maior valor agregado na entressafra, e a capacidade estática da unidade armazenadora, não gerando conflito entre a colheita da soja verão e o milho safrinha, já que nesta simulação o armazém a ser implantado possui dois silos metálicos com capacidade de 3.030 toneladas cada.

Foi analisado o histórico de preços disponíveis de janeiro de 2011 a janeiro de 2016 para o preço do milho (Figura 1) e soja (Figura 2) disponíveis em Sorriso (MT), sendo que foram deflacionados pelo índice IPCA-15 data base janeiro de 2011. Para encontrar o ganho de comercialização no melhor período, foi obtida a média do preço da soja disponível entre os meses de julho e dezembro de 2011 a 2015 e, excepcionalmente, de julho à primeira quinzena de agosto de 2016, sendo este R \$ 45,07 por saca. Para obter o lucro na venda da soja neste período foi subtraído da média do período referente, sempre ao primeiro semestre de cada ano de janeiro a junho de 2011 a 2016, cujo valor médio do preço de venda foi de R\$ 38,90 por saca. Desta forma, a vantagem de vender (ganho de venda; Tabela 4) o produto no segundo semestre de cada ano é de $\mathrm{R} \$ 6,17$ por saca.

Os preços mais baixos para o milho estiveram nos meses de julho a setembro para 2013 e os mais altos em março, exceto em 2016 (Figura 1), quando houve falta do produto no mercado. Com isso, realizou-se a média dos preços do milho disponível em Sorriso nos meses de fevereiro a maio de 2011 a 2016, caracterizando o melhor momento para a comercialização do cereal, cujo valor obtido foi de R \$ 14,93 por saca. Em contra partida foi realizada a média da série histórica de janeiro de 2011 a agosto de 2016 e o resultado obtido foi de $\mathrm{R} \$ 12,35$ por 
saca para venda, onde a subtração dessas médias (ganho de venda; Tabela 4) foi de $\mathrm{R} \$ 2,58$ por saca. Esse movimento ocorre principalmente devido à falta de armazenagem do produto que compete com a soja por espaço físico e a falta de negociação prévia com a agroindústria.

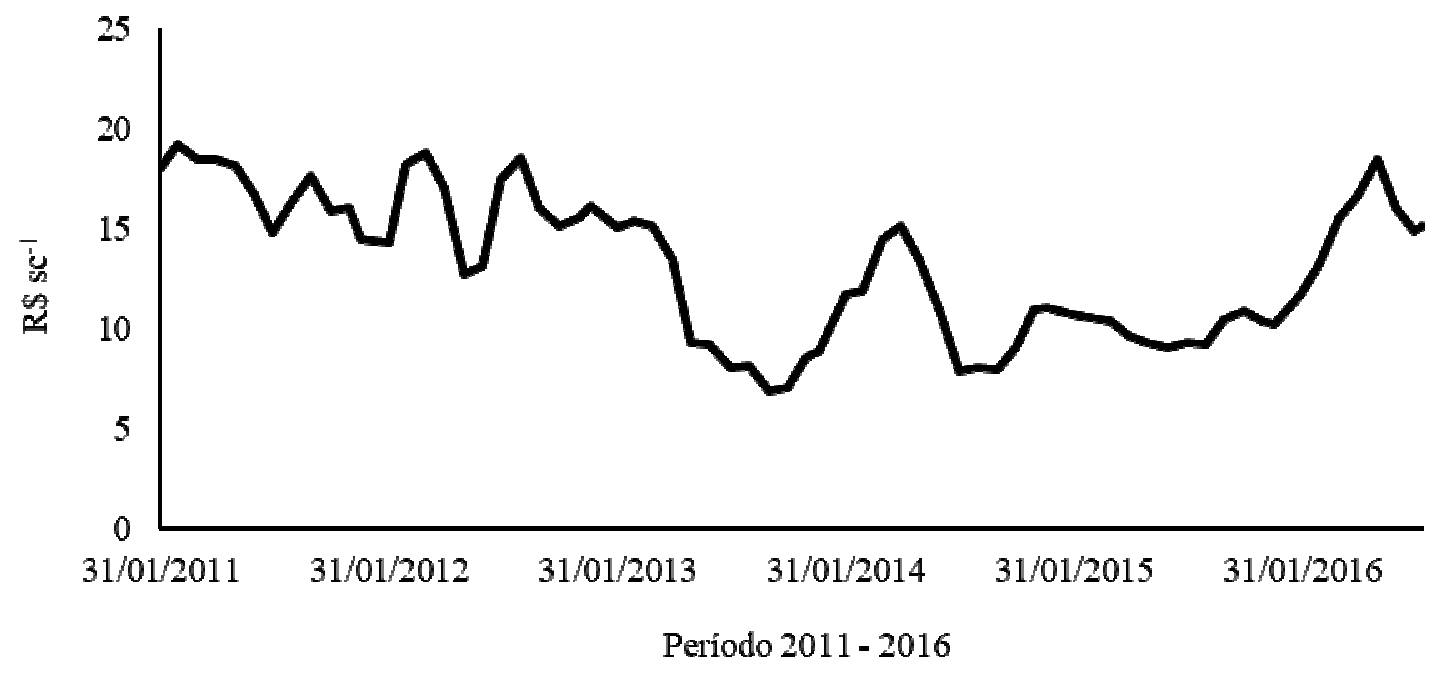

Figura 1- Histórico dos preços diários do milho efetuados em Sorriso (MT)

Fonte: IMEA (2016b)

Para os preços da soja, o mais elevado ocorre no segundo semestre de cada ano (Figura 2), pois são os meses que antecedem a colheita da safra de soja na macrorregião Médio Norte do estado. Porém, esta é mais dinâmica que o milho, sofrendo influência de mercados externos, com preço formado pela "Chicago Of Board Trade" (CBOT) no estado de Illinois nos Estados Unidos da América (EUA). Desta forma, utilizou-se um ganho de R\$ 2,58 e R\$ 6,17 a mais por saca de milho e soja, respectivamente, como incremento de preço por otimização da comercialização nos meses em que este tende a ser historicamente superior ao do período de safra. 


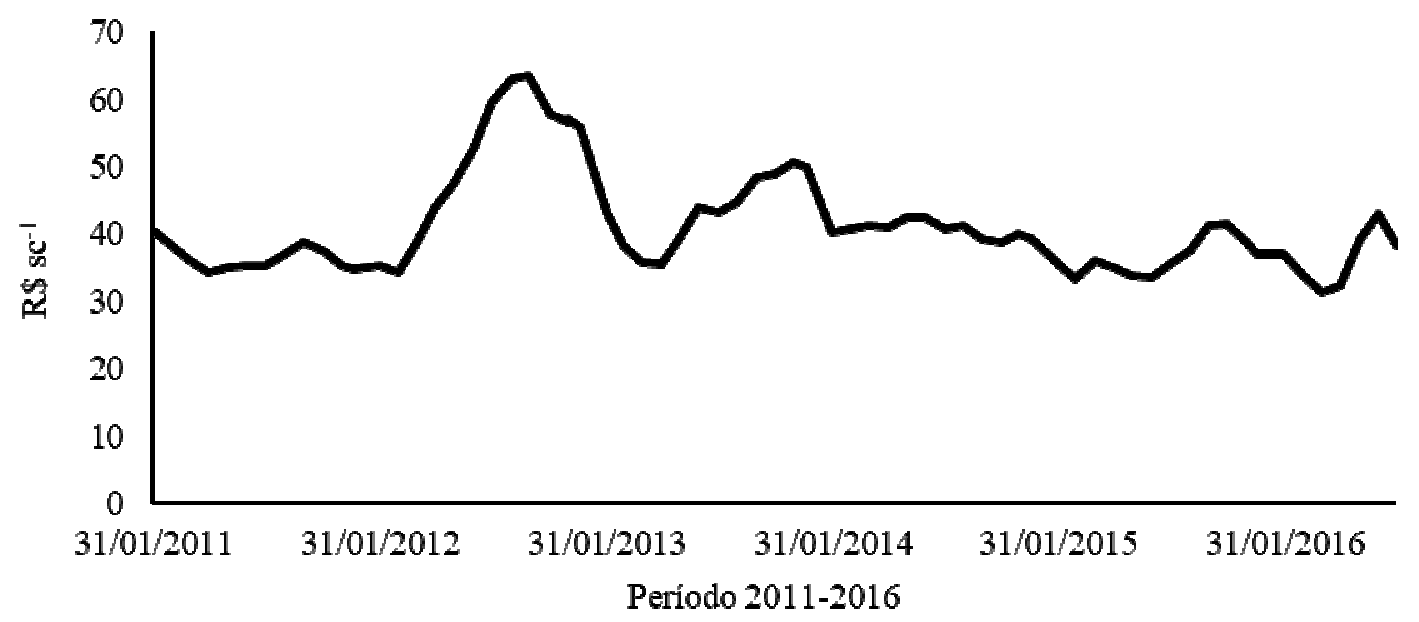

Figura 2- Histórico dos preços diários da soja efetuados em Sorriso (MT)

Fonte: IMEA (2016b)

\subsection{Financiamento}

Foi utilizada a linha de crédito do Banco Nacional do Desenvolvimento Econômico e Social (BNDES) para financiar todos os custos referentes à implantação e instalação da planta armazenadora e das máquinas para beneficiamento do grão. Conforme a circular SUP/AGRIS $\mathrm{n}^{\circ}$ 15/2016 do BNDES, que determina a linha de crédito destinada à financiamento de construção e ampliação de armazéns PCA, a taxa de juros aplicada é de 8,5\% ao ano, com prazo para financiamento de 180 meses, com 36 meses de carência, com cobrança apenas dos juros anuais. A linha de crédito contempla $100 \%$ do projeto, para empreendimentos individuais ou coletivos com teto de $\mathrm{R} \$ 20.000 .000,00$ para produtos com características do BNDES AUTOMÁTICO [BNDES, 2016]. A capacidade estática do empreendimento não pode ser superior a $100 \%$ da produção esperada para o mutuário ou o grupo envolvido. Os recursos para a linha tem origem no Financiamento de Máquinas e Equipamentos (FINAME), pré-definido pelo Manual do Crédito Rural (MCR).

As parcelas do financiamento do exemplo estudado estão descritas na Tabela 3, com os lançamentos anuais, cujas três primeiras não há amortização do capital. A metodologia utilizada pelo BNDES é o Sistema de Amortização Continuo (SAC). 
Tabela 3- Composição das parcelas do financiamento através da linha de crédito PCA (R\$

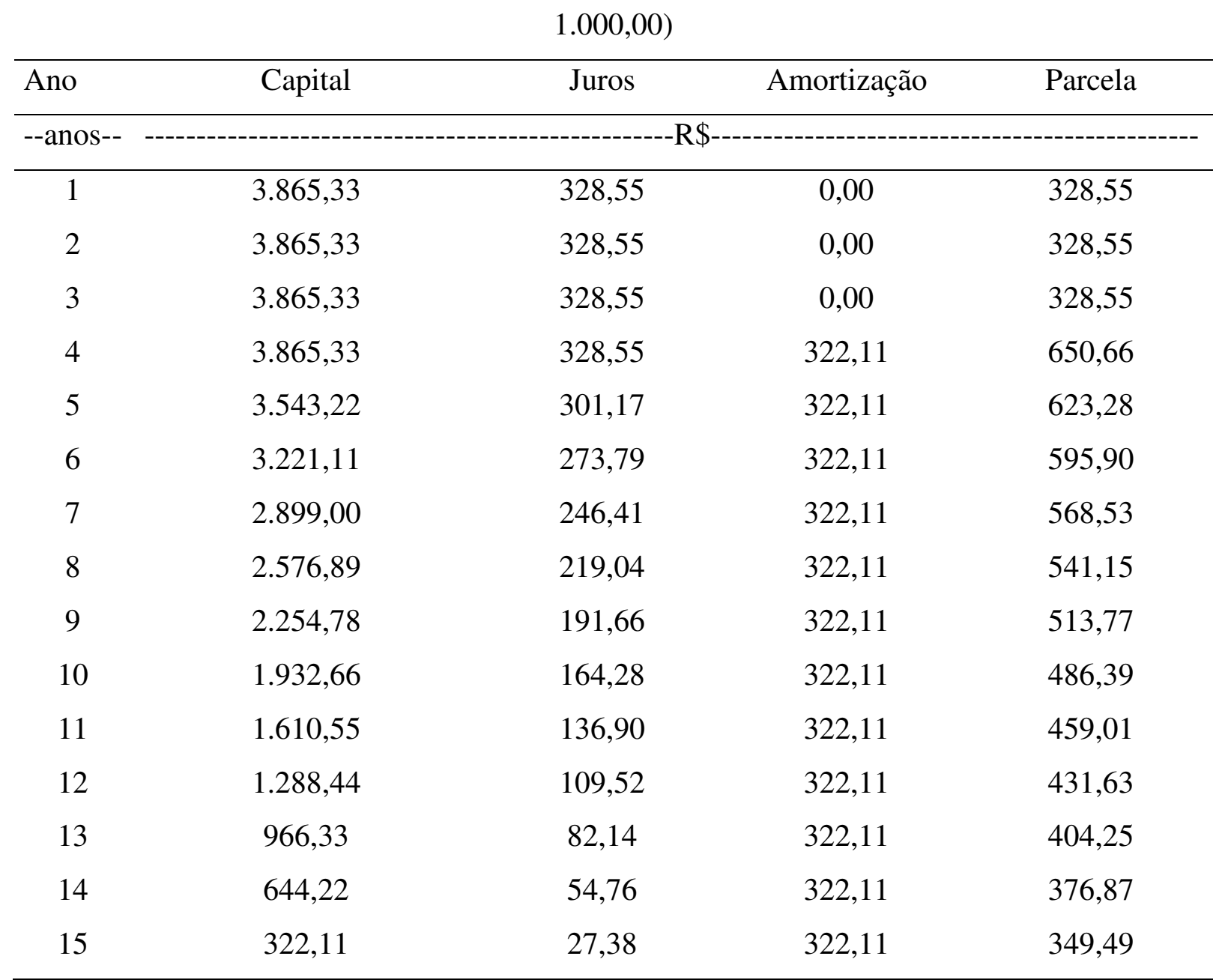

Fonte: Cálculos elaborados pelo autor

$\mathrm{Na}$ primeira coluna há os períodos em anos para amortização do financiamento (Tabela 3), na segunda o saldo devedor, na terceira o valor dos juros que compõem a parcela, de forma decrescente, pois incidem os juros sobre o saldo devedor a uma taxa de 8,5\% a.a. sem a incidência de Imposto sobre Operação Financeira (IOF). Os juros são decrescentes devido à amortização do capital (SAC). Na coluna amortização, é apresentado o valor a ser amortizado por período. Nos três primeiros períodos não há amortização, pois se trata do período de carência do financiamento. Na coluna parcela, está descrito o valor da prestação anual do financiamento (juros + amortização do período) que será cobrado na seção de custos fixos do fluxo de caixa juntamente com os custos fixos definidos na Tabela 1.

2.5 Fluxo de caixa do projeto 
O fluxo de caixa foi definido a partir dos lançamentos divididos em custo fixo, custo variável, receitas, soja e milho, depreciação e fluxo de caixa (Tabela 4). Na seção dos custos fixos estão agregados os custos fixos (Tabela 1) mais a soma da parcela anual do financiamento (Tabela 3). Nos custos variáveis estão descritos os valores dos custos referentes à Tabela 1. Na coluna de receitas estão descritos as receitas (Tabela 5) para soja e para o milho. Na coluna depreciação, foram aplicados os valores descritos na soma da Tabela 2. Na coluna fluxo de caixa, foi realizada a subtração da soma das receitas (soja e milho) pela soma dos custos fixo e variável (Tabela 4).

Tabela 4-Fluxo de caixa do projeto

\begin{tabular}{|c|c|c|c|c|c|c|}
\hline \multirow[t]{2}{*}{ Anos } & $\begin{array}{l}\text { Custo } \\
\text { fixo } \\
\text { (A) }\end{array}$ & $\begin{array}{c}\text { Custo } \\
\text { variável } \\
\text { (B) }\end{array}$ & \multicolumn{2}{|c|}{ Receitas } & Depreciação & \multirow[t]{2}{*}{$\begin{array}{c}\text { Fluxo de } \\
\text { caixa } \\
\text { F=C+D-A-B }\end{array}$} \\
\hline & & & Soja (C) & $\begin{array}{c}\text { Milho } \\
\text { (D) }\end{array}$ & & \\
\hline $1^{\circ}$ & 587,06 & 214,62 & 473,54 & 488,32 & 278,89 & 160,18 \\
\hline $2^{\circ}$ & 587,06 & 214,62 & 473,54 & 488,32 & 278,89 & 160,18 \\
\hline $3^{\circ}$ & 587,06 & 214,62 & 473,54 & 488,32 & 278,89 & 160,18 \\
\hline $4^{\circ}$ & 909,17 & 214,62 & 473,54 & 488,32 & 278,89 & $-161,93$ \\
\hline $5^{\circ}$ & 881,79 & 214,62 & 473,54 & 488,32 & 278,89 & $-134,55$ \\
\hline $6^{\circ}$ & 854,41 & 214,62 & 473,54 & 488,32 & 278,89 & $-107,17$ \\
\hline $7^{\circ}$ & 827,03 & 214,62 & 473,54 & 488,32 & 278,89 & $-79,79$ \\
\hline $8^{\circ}$ & 799,65 & 214,62 & 473,54 & 488,32 & 278,89 & $-52,41$ \\
\hline $9^{\circ}$ & 772,28 & 214,62 & 473,54 & 488,32 & 278,89 & $-25,03$ \\
\hline $10^{\circ}$ & 744,90 & 214,62 & 473,54 & 488,32 & 278,89 & 2,35 \\
\hline $11^{\circ}$ & 717,52 & 214,62 & 473,54 & 488,32 & 39,41 & 29,73 \\
\hline $12^{\circ}$ & 690,14 & 214,62 & 473,54 & 488,32 & 39,41 & 57,11 \\
\hline $13^{\circ}$ & 662,76 & 214,62 & 473,54 & 488,32 & 39,41 & 84,49 \\
\hline $14^{\circ}$ & 635,38 & 214,62 & 473,54 & 488,32 & 39,41 & 111,87 \\
\hline $15^{\circ}$ & 608,00 & 214,62 & 473,54 & 488,32 & 39,41 & 139,25 \\
\hline $16^{\circ}$ & 258,51 & 214,62 & 473,54 & 488,32 & 39,41 & 488,74 \\
\hline $17^{\circ}$ & 258,51 & 214,62 & 473,54 & 488,32 & 39,41 & 488,74 \\
\hline
\end{tabular}




\begin{tabular}{lllllll}
$18^{\circ}$ & 258,51 & 214,62 & 473,54 & 488,32 & 39,41 & 488,74 \\
$19^{\circ}$ & 258,51 & 214,62 & 473,54 & 488,32 & 39,41 & 488,74 \\
$20^{\circ}$ & 258,51 & 214,62 & 473,54 & 488,32 & 39,41 & 488,74 \\
\hline
\end{tabular}

Fonte: Cálculos do autor

O fluxo de caixa é um arranjo de entradas e saídas com base nas receitas e despesas do projeto, sendo esse instrumento um dos principais para a avaliação de empresas (MACÁRIO, 2009). Seus custos foram definidos por custo fixo - CF (parcela do financiamento da unidade armazenadora e os valores gastos com salário da mão-de-obra perene) e custo variável - CV (custos com limpeza, secagem e padronização dos grãos, mão de obra sazonal e o custo com a quebra técnica do grão). Os custos (CF e CV), descritos na Tabela 1, foram obtidos a partir de pesquisa com produtores rurais da região do município de Sorriso (MT), sendo subtraídos das receitas de forma anualizada, definindo-se, então, o fluxo de caixa. A depreciação não foi utilizada para fins de dedução da receita, uma vez que se trata de um custo apenas contábil para fins de tributação.

Os três primeiros períodos apresentarão valores do fluxo de caixa positivos, pois refletem o período no qual há carência no financiamento (Tabela 4). Entre o quarto e o nono períodos, os valores dos fluxos de caixa serão negativos, pois as parcelas de amortização do financiamento serão mais altas devido ao saldo devedor, sendo que na composição dos custos totais, a parcela do financiamento representará $57,90 \%$ no quarto período, reduzindo-se para $42,48 \%$ no décimo quinto período, quando será amortizada a última parcela, apresentando o impacto da parcela nos custos do projeto.

O fluxo de caixa se tornará positivo a partir do décimo período, momento em que as parcelas do financiamento para construção da unidade armazenadora estarão com menor incidência de juros devido à amortização constante (SAC), com o valor regressivo das parcelas.

\subsection{Análise econômica}

Para testar a viabilidade econômica, foi utilizado o Valor Presente Líquido [VPL], a Taxa Interna de Retorno [TIR] e o "payback" Descontado, recursos da matemática financeira úteis para testar a rentabilidade de investimentos. O VPL é calculado a partir do retorno no tempo dos valores do fluxo de caixa através da taxa de atratividade mínima do projeto, onde os fluxos de caixa futuros recebem o desconto desta taxa se equiparando todos no instante ReFAE - Revista da Faculdade de Administração e Economia, v. 9, n. 2, p. 166-190, 2019 
inicial (SAMENEZ, 2007). Para esse projeto foi escolhida a taxa de $2,0 \%$ ao ano como taxa de reinvestimento, pois está mais próxima a uma taxa real sem influência da inflação.

Para calcular qual a rentabilidade em valores percentuais, foi utilizada a TIR. Essa ferramenta analisa os fluxos de caixa e determina uma taxa média de rendimento para o investimento não levando em consideração a taxa de reinvestimento, enquanto o "payback" possibilita mensurar o tempo necessário para reaver o valor investido inicialmente ou que foi desembolsado nos fluxos de caixa do objeto de análise. Sua metodologia consiste em trazer os valores desembolsados e os saldos superavitários para o tempo inicial através da taxa de reinvestimento do projeto até que os saldos positivos sejam iguais ao saldo desembolsado, sendo o período/tempo expresso em anos, meses e dias necessários para que o projeto apresente alguma viabilidade econômica (SAMANEZ, 2007).

\section{RESULTADOS E DISCUSSÃO}

\subsection{Receitas do Projeto}

As receitas anuais para demostrar os ganhos na utilização de armazenamento próprio estão descritas na Tabela 5. Foi considerada a receita com a venda do resíduo do beneficiamento da soja e do milho, um subproduto que antes era comercializado pelas tradings ou armazéns gerais e não havia remuneração ao produtor. $\mathrm{O}$ valor com a venda de resíduo de soja e milho gerará economia na propriedade referência no valor de $\mathrm{R} \$ 17.400,00$ para soja e de $\mathrm{R} \$ 25.080,00$ para o milho.

Tabela 5- Origem das receitas do projeto

\begin{tabular}{lcc}
\hline Descrição & Soja & Milho \\
\hline Produção total esperada & ----- Toneladas------- \\
\hline & 3.480 & 6.600 \\
\hline $\begin{array}{l}\text { Resíduo do beneficiamento } \\
\text { Economia no transporte até a unidade }\end{array}$ & 5,00 & 3,80 \\
armazenadora privada & 17,40 & 9,95 \\
Redução no custo com & & \\
beneficiamento privado & 15,50 & 20,83
\end{tabular}


Redução no custo com armazenagem privada.

Ganho na venda do produto na entre safra

Fonte: pesquisa com produtores locais e IMEA (2016a)

Os ganhos com economia de frete (da propriedade à unidade armazenadora terceirizada mais próxima) será no valor de $R \$ 60.552,00$ para soja e $R \$ 65.650,00$ para o milho (Tabela 5). Ganhos com frete em estudo análogo também foi apresentado por Gottardo e Cestari (2008), representando 7,03\% da receita de um armazém no município de Campo Mourão-PR, valor inferior ao observado neste projeto, que foi de $13,12 \%$ da receita total, tendo em vista as distâncias e o valor do frete por tonelada serem maiores no estado de MT.

$\mathrm{O}$ custo com armazenagem terceirizada ( $\mathrm{R} \$ 36.540,00$ para soja e $\mathrm{R} \$ 132.000,00$ para o milho) também foi incorporado como receita (Tabela 5), uma vez que o produtor reduz esse gasto por ele próprio secar e padronizar toda a sua produção, evitando os descontos e o custo de beneficiamento de $\mathrm{R} \$ 15,50 \mathrm{t}^{-1}$ para soja e de $\mathrm{R} \$ 20,83 \mathrm{t}^{-1}$ para o milho na entrega em beneficiadoras terceirizadas, o que representará $R$ \$ 53.940,00 para soja e $R \$ 137.500,00$ para o milho. Segundo Webber (2011), o custo com armazenagem de grãos em unidades privadas no estado do Paraná (PR) apresentava o valor de $\mathrm{R} \$ 14,31 \mathrm{t}^{-1}$ (valor corrigido pelo índice da inflação IPCA de jan. 2009 a jan. 2016), demonstrando que o estado do MT possui armazenagem com maior custo que no estado do PR, dada a sua localização geográfica distante dos principais portos de exportação/importação do país, o que reflete, sobremaneira, nos custos dos insumos necessários à atividade agrícola.

Também os ganhos anuais de comercialização (ganho na venda; Tabela 5) para a soja serão de $\mathrm{R} \$ 305.111,43$ e de $\mathrm{R}$ \$ 128.094,97 para o milho, haja vista que o produtor obterá vantagem em utilizar o acondicionamento próprio, otimizando a comercialização de sua produção. Segundo Müller (2014), o ganho por saca na comercialização direta de soja, quando proprietário da unidade armazenadora, foi de $\mathrm{R} \$ 7,00$ enquanto que para o milho foi de R \$ 4,00 no estado do Rio Grande do Sul (RS). Contudo, o presente projeto utilizou valores diferentes, pois o estado do MT possui diversos gargalos de infraestrutura e está distante do mercado consumidor e/ou exportador.

Desta forma, o projeto gerará receita bruta anual de $\mathrm{R} \$ 473.543,43$ e $\mathrm{R} \$ 488.324,97$ para soja e milho, respectivamente, sendo a soma o valor de $\mathrm{R} \$ 961.868,40$ (Tabela 5). 
Assim, considerando que para secar/beneficiar 168.000 sacas, mas com armazenamento de 101.000 sacas, a receita bruta por saca será de $\mathrm{R} \$ 5,73$, considerando ainda que o custo total anual da unidade armazenadora, dividido pelas 168.000 sacas que serão beneficiadas, será de $\mathrm{R} \$ 2,82$ por saca, o resultado operacional (sem descontar a parcela do financiamento) será de $\mathrm{R} \$ 2,91$ por saca de grão, o que garantirá, em termos percentuais, ao projeto eficiência de $49,19 \%$ em relação à receita e aos custos.

\subsection{Teste de viabilidade econômica}

Os cálculos foram efetuados a partir dos valores dos fluxos de caixa descritos na Tabela 4.

Conforme a Tabela 6, o VPL do projeto apresentou valor positivo para o seu horizonte de vida útil (20 anos) no valor de R\$1.996.262,01. Paz e Aragão (2016), estudando a viabilidade econômica da construção de uma unidade armazenadora em propriedade rural de Lagoa Vermelha (RS), constataram haver um VPL de R\$ 526.230,23 para o empreendimento mencionado, demostrando que o projeto também apresentou viabilidade econômica, quando medida por tal indicador financeiro, para um projeto com metade da capacidade estática deste. Para decisão de melhoria na eficiência logística, Martins et al. (2005) mensuraram a viabilidade econômica da construção de unidade armazenadora própria para uma propriedade de 317 hectares no oeste do PR no valor de R\$420.467,92, sendo observado êxito na eficiência logística da propriedade rural.

Tabela 6- Indicadores de viabilidade econômica do projeto

\begin{tabular}{lc}
\hline Descrição & Valor \\
\hline Valor presente líquido (VPL) & $1.996 .262,01$ \\
& $--------\%$-------- \\
\hline Taxa interna de retorno (TIR) & Não há TIR válida \\
Taxa interna de retorno modificada (TIRM) & 20,02 \\
Payback descontado & 12 anos, 04 meses e 27 dias
\end{tabular}

Fonte: Cálculos do autor 
A taxa interna de retorno possível com o projeto não se apresentou válida devido ao fluxo de caixa do projeto ser não convencional, gerando fluxos de caixas negativos e positivos ao longo da duração do projeto (Tabela 6). Conforme metodologia apresentada, a taxa interna de retorno modificada apresentou valor de $20,02 \%$ ao ano, sendo que essa taxa considera a taxa de reinvestimento do projeto de 2,0\% ao ano. O estudo apresentado por Belusso (2016), com capacidade estática duas vezes maior que a deste projeto, apresentou TIR de $9 \%$ ao ano, porém o mesmo utilizou um prazo de 10 anos, além de o projeto ser elaborado com recursos próprios, gerando um grande desembolso inicial. Para Martins et al. (2006), a eficiência logística de unidade armazenadora própria gerou $21,88 \%$ de taxa interna de atratividade modificada, sendo muito próxima à taxa obtida neste projeto.

Conforme o "payback" descontado, o projeto pagará todo o valor de implantação da unidade armazenadora em 12 anos, 04 meses e 27 dias (Tabela 6), utilizando somente as receitas e os custos que não envolvam a parcela do financiamento, uma vez que o objetivo desse indicador é saber o tempo necessário que o projeto tem capacidade de auferir receita capaz de quitar o valor inicialmente investido. Contudo, como o financiamento contempla 100\% do custo de implantação (sem desembolso inicial do produtor rural), foi desconsiderada a parcela para o cálculo do "payback" descontado.

Conforme apresentado, o trabalho possibilitará ao produtor rural gerar ganho de escala na comercialização da sua produção, uma vez que não dependerá de armazenamento terceirizado, que é sujeito à disponibilidade e ao preço de traders e cerealistas. Esse recurso superavitário poderá ser, então, utilizado pelo produtor para melhorias da sua unidade de produção, como, por exemplo, realizar novos investimentos na modernização de suas máquinas, investimentos em correção do solo, controle de pragas e até na implantação de um sistema de irrigação para produzir uma terceira safra no período de estiagem, fenômeno natural típico no bioma Cerrado, otimizando a renda de sua propriedade rural, vindo ao encontro do que Belusso (2016) verificou ao mencionar que o produtor rural poderá optar pela construção de unidade armazenadora própria, tendo em vista os ganhos do projeto serem consideravelmente satisfatórios, assim como Azevedo et al. (2008) acreditam que o estado de MT terá grande importância quanto a capacidade estática nacional, uma vez que o coeficiente angular da curva de variação da capacidade estática dos últimos 30 anos apresentou valor positivo, dando confiança ao produtor rural que queira investir na construção de sua unidade armazenadora de grãos, gerando economia e potencializando os ganhos com a atividade agrícola. 


\section{CONSIDERAÇÕES FINAIS}

O projeto demonstrou viabilidade econômica, contudo, o fator que mais causará impacto no fluxo de caixa será as parcelas do financiamento, gerando fluxos de caixa negativos nos períodos onde haverão maiores valores das parcelas. Desta forma, linhas de financiamento mais baratas podem melhorar a viabilidade do projeto.

A estrutura física possui prazo de depreciação maior que o período do fluxo de caixa apresentado neste projeto, possibilitando ao produtor rural usufruir da unidade armazenadora por um prazo superior ao definido.

Desta forma, o financiamento de $100 \%$ da unidade armazenadora para uma propriedade de 1.000 hectares, é um atrativo para o produtor rural por possibilitar melhor comercialização de sua produção pós-colheita, fortalecendo o processo produtivo, podendo, inclusive, gerar receitas com os resíduos que não entrariam no seu fluxo de caixa, além da independência de empresas terceirizadas, podendo ele mesmo controlar a qualidade do seu produto (secagem e beneficiamento), reduzindo os descontos na classificação dos grãos entregue às traders, preservando suas receitas, uma vez que o seu intuito não é ser uma empresa de beneficiamento e armazenagem de forma isolada, mas agregar valor à produção e gerar mais ganhos em sua propriedade rural.

\section{REFERÊNCIAS}

AZEVEDO, L. F.; OLIVEIRA, T. P.; PORTO, A. G.; SILVA, F. S. Capacidade estática de armazenamento de grãos no Brasil. XXVIII encontro nacional de engenharia de produção a integração de cadeias produtivas com a abordagem da manufatura sustentável. 2008.

BANCO NACIONAL DE DESENVOLVIMENTO ECONÔMICO E SOCIAL - BNDES. Circular sup/agris $n^{0}$ 15/2016, de 07 de julho de 2016. Dispões sobre o programa para construção e ampliação de armazéns [PCA]. Disponível em: http://www.bndes.gov.br/SiteBNDES/export/sites/default/bndes_pt/Galerias/Arquivos/produt os/download/circulares/2016/16Circ15_AGRIS.pdf. Acesso em: 21 jan. 2015. 2016.

BATAlHA, M. O. Gestão Agroindustrial. $3^{\circ}$ Edição, Editora Atlas, São Paulo, SP, Brasil. 2011. 573 p. 
BELUSSO, N. A. Análise da viabilidade econômica para a construção de um armazém de grãos em Nova Ubiratã - MT. Monografia de Bacharel em Ciências Econômicas. Universidade Federal do Mato Grosso, Cuiabá, MT, Brasil. 2015.

BRASIL. Lei n. 12973, de 13 de maio de 2014. Brasília - DF. Disponível em: <http://www.planalto.gov.br/ccivil_03/_ato2011-2014/2014/Lei/L12973.htm >. Acesso em: 03 set. 2016. 2014.

BURKOT, C. R. A qualidade desejada na secagem e armazenagem de grãos em uma cooperativa no município de Ponta Grossa - PR. Revista de Gestão e Organizações Cooperativas, Santa Maria, v. 1, n. 2, p. 7-18. 2014

COGO, C. Falta espaço, sobra prejuízo a todos. Revista A Granja, Edição 774: p. 12-16. 2013.

COMPANHIA NACIONAL DE ABASTECIMENTO - CONAB. Acompanhamento da safra brasileira: grãos. v. 2, Safra 2014/2015 - sétimo levantamento, Brasília: Conab. 16 p. 2015a.

COMPANHIA NACIONAL DE ABASTECIMENTO - CONAB. Acompanhamento da safra brasileira: grãos. v. 3, Safra 2015/2016 - décimo levantamento, Brasília: Conab. 18 p. $2015 b$.

DAmbrosio, M. A.; REDIVO, A.; REDIVO, A. R.; FERREIRA, G. A. Custos da padronização e armazenagem da soja em armazém próprio no município de Sorriso - MT. Revista Contabilidade \& Amazônia, Sinop, v. 2, n. 1, p. 27-28. 2009.

ESCOLA SUPERIOR DE AGRICULTURA LUÍZ DE QUEIROZ - ESALQ. Grupo de Pesquisa e Extensão em Logística Agroindustrial Esalq-log. Projeto SIARMA, Relatório de indicadores de preço de armazenagem: Centro-Oeste. 2015.

GOTTARDO. F. A.; CESARI JUNIOR, H. Viabilidade econômico-financeira de implantação de um sistema de armazenagem de grãos: um estudo de caso em uma média propriedade rural em campo mourão - PR. Revista em Agronegócios e Meio Ambiente, Maringa, v. 1, n. 1, p. 55-76. 2008. 
INSTITUTO BRASILEIRO DE GEOGRAFIA E ESTATÍSTICA - IBGE. Anuário das cidades.

Disponível

em:

$<$ http://www.cidades.ibge.gov.br/xtras/perfil.php?lang=\&codmun=510792\&search=matogrossolsorriso>. Acesso em: 08 ago.2016. 2016.

INSTITUTO MATOGROSSENSE DE ECONOMIA AGROPECUÁRIA - IMEA. Mapa de macrorregiões do IMEA. Disponível em: $<$ http://www.imea.com.br/upload/publicacoes/arquivos/justificativamapa.pdf $>$. Acesso em: 04 Out. 2016. 2010.

INSTITUTO MATOGROSSENSE DE ECONOMIA AGROPECUÁRIA - IMEA. Boletim $\begin{array}{lllll}\text { Semanal } & \mathbf{n}^{\mathbf{0}} & \mathbf{3 8 4} & \text { Disponível }\end{array}$ <http://www.imea.com.br/upload/publicacoes/arquivos/R403_2015_12_18_BSMilho.pdf>. Acesso em: 20 Out. 2016. 2015a.

INSTITUTO MATOGROSSENSE DE ECONOMIA AGROPECUÁRIA - IMEA. Boletim Semanal $\quad \mathbf{n}^{\circ} \quad \mathbf{3 8 5} . \quad$ Disponível em: <http://www.imea.com.br/upload/publicacoes/arquivos/R404_2015_12_18_BSSOJA.pdf>. Acesso em: 20 Out. 2016. 2015b.

INSTITUTO MATOGROSSENSE DE ECONOMIA AGROPECUÁRIA - IMEA. Primeira estimativa da safra de soja - 2016/17. Disponível em: <http://www.imea.com.br/upload/publicacoes/arquivos/R410_CPSoja_09_2015.pdf>. Acesso em: 13 ago. 2016. 2016a.

INSTITUTO MATOGROSSENSE DE ECONOMIA AGROPECUÁRIA - IMEA. Primeira estimativa da safra de milho - 2016/17. Disponível em: <http://www.imea.com.br/upload/publicacoes/arquivos/R410_CPMilho_11-2015.pdf>. Acesso em: 13 ago. 2016. 2016b.

MACÁRIO, R. A. H. A importância da gestão do fluxo de caixa no controle da inadimplência. Monografia de especialização em gestão de negócios financeiros. Universidade Federal do Rio Grande do Sul, Porto Alegre, RS, Brasil. 2009. 50 f.

MANELLA, M. Q.; BOIN, C. Alimentos alternativos: Resíduo da limpeza de soja. Disponível em: 
$<$ http://www.beefpoint.com.br/radarestecnicos/nutricao/alimentosalternativosresiduodalimpez adesoja4799/>. Acesso em: 24 de out. 2016. 2000.

MARTINS, R. S.; REBECHI, D.; PRATI C. A.; CONTE, H. Decisões estratégicas na logística do agronegócio: compensação de custos transporte-armazenagem para a soja no estado do Paraná. Revista de Administração Contemporânea, Curitiba, v. 9, n. 1, p. 70-75, 2005 .

MINISTÉRIO DA AGRICULTURA PECUÁRIA E ABASTECIMENTO - MAPA. Governo destina $\mathbf{R}$ \$ 1,4 bilhão para financiar armazéns em fazendas. Disponível em: $<$ http://www.agricultura.gov.br/comunicacao/noticias/2016/05/governo-destina-rs-1-bilhaopara-financiar-armazens-em-fazendas>. Acesso em: 16 jul. 2016. 2016.

MÜLLER, J. Estudo de viabilidade econômica e financeira para sistemas de armazenagem de grãos. Monografia de Bacharel em ciências econômicas. Universidade regional do Noroeste do estado do Rio Grande do Sul, Ijui, RS, Brasil. 2014. 132 f.

NOGUEIRA JUNIOR, S.; TSUNECHIRO, A. Pontos críticos da armazenagem de grãos no Brasil. IEA. Disponível em:<http://www.iea.sp.gov.br/out/LerTexto.php?codTexto=12111>. Acesso em: 16 mai. 2016. 2011.

PAZ, M. V.; ARAGÃO, T. R. de P. Viabilidade econômica da construção de uma unidade armazenadora em propriedade rural de Lagoa Vermelha (RS). Revista Ipecege, Piracicaba, v. 2, n. 1, p. 67-78, 2016.

PEREIRA, E. S.; PAIVA, P. C. DE A.; TIESENHAUSEN, I. M. E. V. VON.; POZZA, P. C.; ARRUDA, A. M. V. Degradação da matéria seca, proteína bruta e fibra em detergente neutro de silagens de capim-elefante adicionadas de resíduos do beneficiamento do milho e da soja. Revista Brasileira de Zootecnia, Viçosa, v. 29, n. 6, 2355-2357, 2000.

RECEITA FEDERAL DO BRASIL - RFB. Instrução Normativa SRF n⿳ 162, de 31 de dezembro de 1998. Fixa prazo de vida útil e taxa de depreciação dos bens que relaciona. Publicada no DOU de 07/01/1999, seção, 5 p. 1988. 
REGITANO-D'ARCE, M.A.B. Pós colheita e armazenamento de grãos. Disponível em: $<$ http://www.esalq.usp.br/departamentos/lan/pdf/Armazenamentodegraos.pdf>. Acesso em: 16 jul. 2016. 2009.

SAMANEZ, C. P. Matemática Financeira: aplicações à análise de investimentos, 4a ed. Pearson Prentice Hall, São Paulo, 2007.

WEBBER, E. F. Viabilidade técnico-econômica na armazenagem de grãos no Paraná. Monografia de Bacharel em Agronegócio, Universidade federal do Paraná, Curitiba, PR, Brasil. 2011. $55 \mathrm{f}$. 
Anexo A- Custo de implantação de unidade armazenadora composta de dois silos metálicos verticais para 101.000 sacas de $60 \mathrm{~kg}$ de grãos

\begin{tabular}{lccc}
\hline Descrição & Quantidade & Unitário & Valor Total \\
\hline Serviços iniciais & & & \\
\hline & Unidade & $---------R \$---------$ \\
Placa de obra & - & 250,00 & 250,00 \\
Ligação provisória de água & - & $1.850,00$ & $1.850,00$ \\
Ligação provisória de energia & - & 124,00 & 124,00 \\
Casa do engenheiro e escritório temporário & - & $1.795,00$ & $1.795,00$ \\
\hline
\end{tabular}

Bases para 02 silos semi-cônicos modelo 18 para 50.500 sacas de grãos cada

Casa temporária para guarda de equipamentos

$\begin{array}{llll}\mathrm{m}^{2} & 1.200 & 5,00 & 6.000,00\end{array}$

Terraplanagem

$\begin{array}{llll}\mathrm{m}^{3} & 1.800 \quad 6,00 & 10.800,00\end{array}$

Construção da fundação para

base do silo

Uni 2

$283.333,33 \quad 566.666,67$

Infraestrutura de ferragem para

base do silo

$\begin{array}{llll}\text { Uni } & 2 & 149.457,67 & 298.915,33\end{array}$

Túnel passante 2,00 × 2,00 m

\section{Metros quadrados}

$\mathrm{R} \$$

Casa temporária para guarda de equipamentos

$44,8 \quad 5,00 \quad 224,00$

Terraplanagem

90

6,00

540,00

Construção de piso para o túnel de passante

$\begin{array}{lll}44,8 & 110,00 \quad 4.928,00\end{array}$

Construção da estrutura do túnel de passante

$650 \quad 47.254,67$
$47.254,67$

Saída de emergência

$$
\text { Metros quadrados }
$$

Casa temporária para guarda de

equipamentos

Casa temporária para guarda de $\mathrm{m}^{2}$

$\mathrm{m}^{2}$
1,13

5,00 5,65

100 
equipamentos

Construção da base para saídas

de emerg.

Uni

$1.960,00$

$1.960,00$

Construção de infraestrutura das

saídas

Uni

$1.320,00$

$1.320,00$

Aquisição de esquadrias para

saída

Uni

530,00

530,00

Calçada ao entorno da base

Construção de piso de concreto

entorno

Uni

100

130,00

$13.000,00$

Instalações elétricas $1.750 \mathrm{~W}$ de iluminação e $70 \mathrm{CV}$

\begin{tabular}{lccc}
\hline & Unidades & -------- R $\$---------$ \\
Instalação de quadro de comando & - & $5.000,00$ & $5.000,00$ \\
Instalação elétrica dos motores & 2 & $14.000,00$ & $28.000,00$ \\
Instalação da iluminação & 200 & 300,00 & $60.000,00$ \\
Instalação de tomadas rosca varredora & - & $5.000,00$ & $5.000,00$ \\
\hline
\end{tabular}

Equipamentos do silo e secador

Unidades

$-\mathrm{R} \$-$

Silo plano Jhonrob SLJR-18,3 para $61 \mathrm{mil}$

sacas de grãos

2

$295.350,00$

$590.700,00$

Sistema de aeração fundo troco de cone

modelo SL1856 com ventiladores RFS-

710 e motor de $20 \mathrm{CV}$

2

$49.900,00 \quad 99.800,00$

Transportador helicoidal varredoura THV-

18,3 com motoredutor de $5 \mathrm{CV}, 120$

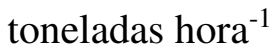

2

$8.550,00$

$17.100,00$

Transportador de correia TCJ-24 com

acionamento por motoredutor de 11,03

KW, 220 t hora $^{-1}$

2

$65.780,00$

$131.560,00$

Conjunto torrador de resíduo TRD-1000

$2 \quad 189.000,00 \quad 378.000,00$

Sistema de termometria medição digital

portátil

2

$21.400,00$

$42.800,00$ 


\begin{tabular}{|c|c|c|c|}
\hline \multirow[b]{3}{*}{ Balança rodoviária com plataforma } & \multirow{3}{*}{$\begin{array}{c}\text { Unidades } \\
-\end{array}$} & \multirow{2}{*}{\multicolumn{2}{|c|}{----------R\$---------- }} \\
\hline & & & \\
\hline & & $66.000,00$ & $66.000,00$ \\
\hline \multicolumn{4}{|l|}{ Gerador de energia } \\
\hline & Unidades & \multicolumn{2}{|c|}{----------R\$--------- } \\
\hline Gerador de energia 250 Kva trifásico & - & $106.020,00$ & $106.020,00$ \\
\hline Instalação e estrutura para gerador & - & $30.000,00$ & $30.000,00$ \\
\hline \multicolumn{4}{|l|}{ Escritório } \\
\hline & Unidades & \multicolumn{2}{|c|}{----------R\$---------- } \\
\hline Construção do escritório & - & $50.000,00$ & $50.000,00$ \\
\hline Computadores & 3 & $2.000,00$ & $6.000,00$ \\
\hline Móveis e cadeiras & - & $12.250,00$ & $12.250,00$ \\
\hline \multicolumn{4}{|l|}{ Silo vertical fundo cônico } \\
\hline & Unidades & \multicolumn{2}{|c|}{----------R\$--------- } \\
\hline Mão de obra para instalação e vedação & 260 & 603,87 & $157.006,20$ \\
\hline Silo cônico metálico e areação & 2 & $323.430,00$ & $646.860,00$ \\
\hline Silo pulmão e silo moega & - & $476.570,00$ & $476.570,00$ \\
\hline \multicolumn{3}{|c|}{ Total dos custos de implantação } & $3.865 .329,52$ \\
\hline
\end{tabular}

Fonte: Orçamentos em Sorriso (MT) 